\title{
Clinical presentation of anxiety among patients with epilepsy
}

\author{
M López-Gómez' \\ M Espinola ${ }^{2}$ \\ J Ramirez-Bermudez ${ }^{3}$ \\ I E Martinez-Juarez ${ }^{4}$ \\ A L Sosa ${ }^{5}$ \\ 'Departments of Neurology; \\ ${ }^{2}$ Neuropsychiatry; ${ }^{3}$ Clinical Research; \\ ${ }^{4}$ Epilepsy, and ${ }^{5}$ Cognition and Behavior, \\ National Institute of Neurology and \\ Neurosurgery of Mexico, Delegación \\ Tlalpan, México
}

\begin{abstract}
Different factors have been related with interictal anxiety, reported in $10 \%-25 \%$ of patients with epilepsy. We determined the frequency of interictal anxiety in 196 patients with active epilepsy in a cross-sectional survey to know which symptoms of anxiety were most frequently reported in patients with epilepsy and to analyze the factors associated with their presence. Patients were assessed with the Beck Depression Inventory (BDI), MontgomeryAsberg Depression Rating Scale (MADRS), and the Hamilton Anxiety Scale (HAMA). Data were analyzed with a logistic regression model. The HAMA ratings revealed that $38.8 \%$ experienced significant anxiety symptoms, as defined by a rating above 18 points. Use of primidone, depression, cryptogenic, and posttraumatic etiologies significantly predicted anxiety after logistic regression. Symptoms related to higher scores on HAMA were anxious mood, tension, insomnia, intellectual function, depressed mood, cardiovascular and genitourinary symptoms. Further studies should be performed to define the role of psychosocial factors in the development and evolution of anxiety among these patients.
\end{abstract}

Keywords: epilepsy, anxiety, depression, neuropsychiatry

\section{Introduction}

Anxiety disorders in epilepsy can be classified according to the temporal relationship with the ictal event. Preictal anxiety precedes the onset of seizures by hours or days (Hughes et al 1993). Postictal fear can last up to 7 days after the seizure. In ictal anxiety, nervousness, fear, anger and irritability can be a partial seizure or an "aura" of a complex partial seizure (Gaitatzis et al 2004); especially among patients with temporal lobe epilepsy (TLE) (10\%-15\% with lateral foci and 15\%-20\% with medial foci) (Gloor et al 1982; Devinsky 2003). Ictal foci on other locations have been related to ictal fear (Hermann and Chhabria 1980). Interictal anxiety is defined as the presence of anxiety symptoms without temporal relationship with seizures (Hermann and Chhabria 1980). It can manifest as clinical anxiety disorders such as panic disorder, general anxiety disorder, or obsessive compulsive disorder (Nickell and Uhde 1999).

The prevalence of interictal anxiety in epilepsy varies among the type of sample studied. Anxiety has been found in 10\%-25\% of patients with epilepsy in the community (Edeh and Toone 1987; Gureje 1991; Jacoby et al 1996); in 19\% of TLE (Currie et al 1971) and in $24.7 \%$ in surgical candidates (Devinsky et al 2005). It is more severe among patients with focal epilepsy (Gureje 1991) and more frequent compared with normal controls and patients with other chronic diseases (Perini et al 1996; Kanner 2002; Gaitatzis et al 2004).

The origin and type of seizures (Piazzini et al 2001), the diagnosis of temporal lobe epilepsy with amygdala involvement (Reynders et al 2005), the use of antiepileptic drugs (McConnell et al 1996; Mula et al 2003), and psychological factors (Hermann 1991) have been related to the development of anxiety in patients with epilepsy. 
However, there is less information regarding which symptoms are related to seizures and which ones are due to anxiety itself.

We performed the present study to determine the frequency of anxiety in patients with epilepsy in order to discover which symptoms of anxiety were the most frequently reported in patients with epilepsy and to analyze the factors associated with its development.

\section{Methods}

We conducted a cross-sectional survey in all consecutive outpatients with epilepsy, defined as recurrent seizures, who attended the National Institute of Neurology of Mexico between September 2006 and March 2007. Patients with symptomatic epilepsy secondary to brain neoplasms, vascular malformations, neurocysticercosis (in all patients with diagnosis of mesial temporal sclerosis, one or more magnetic resonance imaging (MRI) scans were performed to rule out neurocysticercosis), other cerebral infections, cerebrovascular disease, or mental retardation, were excluded as well as patients with a seizure occurring the day of the research interview, or the day before. No patient received antidepressants or antipsychotic medication, and no patient had a prior diagnosis of anxiety or depression. A structured, ad hoc questionnaire was used to register demographical and clinical data. We classified patients in primary generalized and partial epilepsy based on the clinical features of seizures according to the International League Against Epilepsy Classification of Epileptic Seizures (Commission on Classification and Terminology of the International League Against Epilepsy 1981) and supported by the electroencephalogram (EEG) findings. Patients that were classified as primary generalized epilepsy had generalized seizures and generalized epilpetiform activity; while those patients with simple partial, complex-partial and partial-onset secondary generalized seizures and/or focal epileptiform activity were classified as having partial epilepsy.

Patients were assessed with the Beck Depression Inventory (BDI) and Montgomery-Asberg Depression Rating Scale (MADRS), and were classified as having a depressive syndrome when both scales indicated so by means of standard cut-off points (14 points in the BDI and 20 points in the MADRS).

The Hamilton Anxiety Scale (HAMA) was assessed by a clinical neuropsychiatrist. Patients were classified as having an anxiety syndrome when the scale indicated so by means of a standard cut-off point (18 points). The diagnosis of generalized anxiety disorder was confirmed according to
DSM-IV criteria using a semistructured interview performed by a neuropsychiatrist.

A consent form was obtained for all cases, signed by the patient and two family members, as required by the institutional Ethics Committee.

The data analysis was performed with the SPSS version 10 (SPSS Inc., Chicago, IL) program, including descriptive statistics, normality tests, and a bivariate analysis with the use of Pearson's chi-square tests, Mann Whitney tests, and t-tests. A logistic regression model was constructed taking anxiety syndrome as dependent variable and all variables significant in the previous bivariate analysis as independent ones $(p<0.05)$ in order to control for possible confounding variables.

\section{Results}

A total of 196 patients were included during a one year period. $54.1 \%$ were male and $45.9 \%$ were women. The mean age of the total sample was $28 \pm 7$ years. $40.8 \%$ of the patients were married, and $37.8 \%$ had a remunerated job.

Regarding the clinical aspects of epilepsy: $35.7 \%$ of cases were classified as cryptogenic (defined as epilepsy without an structural lesion, without family history, and without studies to determine a possible genetic syndrome); $18.4 \%$ were genetic (those patients with a confirmed genetic syndrome and family history); $14.8 \%$ were related to obstetric complications; $11.2 \%$ were secondary to medial temporal lobe sclerosis; $10.2 \%$ were posttraumatic; and $9.7 \%$ were associated with congenital malformations (structural lesions without family history and not related to obstetric complications, as cortical dysplasia or focal gliosis). The length of disease was variable, with a median of 17 years, range $1-45$. The mean age of onset of seizures was 11.3 years (SD 7.9 years). The mean frequency of seizures was 12.5 (SD 27.95) events in the past year. Only $23.5 \%$ of patients had a good seizure control, defined for purposes of this study as no seizures in the past year; while poor seizure control was defined as one or more seizures in the past year. Patients with polytherapy were $71.9 \%$ of sample. The most commonly used drug was phenytoin $(59.2 \%)$, followed by carbamazepine $(55.1 \%)$, primidone $(31.1 \%)$, valproic acid $(26.5 \%)$, lamotrigine $(6.6 \%)$, and others.

According to both scales (BDI and MADRS) 42.3\% of the patients were considered depressed. The HAMA ratings revealed that $38.8 \%$ experienced significant anxiety symptoms, as defined by a rating above 18 points. The symptoms most frequently reported as positive (items with a score different than 0) among all included patients, and 
among those diagnosed with clinically significant anxiety are reported in Table 1.

There were no differences between anxious and nonanxious patients with epilepsy, regarding gender, marital status, or economical activity. Among the clinical variables, depression, posttraumatic epilepsy, educational degree, polytherapy, use of primidone, and inadequate seizure control were related to the presence of significant anxiety symptoms in the bivariate analysis; but only use of primidone, depression, cryptogenic, and posttraumatic etiologies significantly predicts anxiety among our patients after logistic regression as shown in Table 2. We did not find association between duration of epilepsy, age of onset, and the frequency of partial complex seizures or temporal epilepsy with anxiety among our patients.

\section{Discussion}

In our study, nearly $40 \%$ of our patients had self-reported moderate or severe anxiety. This high frequency could be related to the clinical setting, since our institution is a referral center where the majority of patients have refractory epilepsy. However, socioeconomic factors related to lower quality of life, previously reported in Mexican patients (Alanis-Guevara et al 2005) could play a role in this high frequency of anxiety.

Among our patients, depression was the most important predictor of anxiety. The association between anxiety and depression ( $78 \%$ in our population) was very common, and has been reported in other studies (Cramer et al 2005). This is an important matter in the clinical practice, since depressive-anxious patients are at increased risk for hospitalization, suicide attempt, a more chronic course, and impairment compared to patients with only depression (Zimmerman 2006). The recognition of the comorbidity must be stressed, since it could modify the clinicians' decision for therapy in these patients.

Temporal lobe epilepsy and some antiepileptic drugs, especially topiramate (Mula et al 2003) have been related with interictal anxiety. In our study, anxiety was not associated with temporal lobe epilepsy, and the only medication associated with anxiety among our patients was primidone, fact that could be related to their association with depression, described before (Lopez-Gomez et al 2005). However, the design of the study does not allow us to determine the influence of antiepileptic medication in the outcome of our study.

Another interesting fact was the association between cryptogenic and posttraumatic epilepsies the presence of anxiety in patients with cryptogenic epilepsy could be related both to psychological reactions from the uncertainty of the cause; and neurobiological factors described for the postconcussion syndrome in the posttraumatic epilepsy.

In our patients, the most common isolated symptom of anxiety reported was the presence of fears, but symptoms

Table I Frequency of reported anxiety symptoms in 196 patients with epilepsy

\begin{tabular}{|c|c|c|c|c|}
\hline HAMA items & $\begin{array}{l}\text { All patients included } \\
(N=196)\end{array}$ & $\begin{array}{l}\text { Patients with anxiety } \\
(N=76)\end{array}$ & $\begin{array}{l}\text { Patients without anxiety } \\
(N=120)\end{array}$ & $\mathbf{p}$ \\
\hline Anxious mood & $158(80.6 \%)$ & $76(100 \%)$ & $82(68.3 \%)$ & $<0.001$ \\
\hline Tension & I 56 (79.6\%) & $76(100 \%)$ & $80(66.7 \%)$ & $<0.001$ \\
\hline Fears & 177 (90.3\%) & 72 (94.7\%) & 105 (87.5\%) & 0.728 \\
\hline Insomnia & | 40 (7|.4\%) & $73(96.1 \%)$ & 67 (55.8\%) & $<0.001$ \\
\hline Intellectual function & I 48 (75.5\%) & 72 (94.7\%) & 76 (63.3\%) & $<0.001$ \\
\hline Depressed mood & 154 (78.6\%) & $76(100 \%)$ & $78(65 \%)$ & $<0.001$ \\
\hline Muscular complaints & 150 (76.5\%) & $60(78.9 \%)$ & $90(75 \%)$ & 0.525 \\
\hline Sensory complaints & $158(80.6 \%)$ & $66(86.8 \%)$ & 92 (76.7\%) & 0.079 \\
\hline $\begin{array}{c}\text { Cardiovascular } \\
\text { symptoms }\end{array}$ & $83(42.3 \%)$ & $4 \mathrm{I}(53.9 \%)$ & $42(35 \%)$ & 0.009 \\
\hline Respiratory symptoms & 81 (4I.3\%) & $38(50 \%)$ & $43(35.8 \%)$ & 0.054 \\
\hline $\begin{array}{l}\text { Gastrointestinal } \\
\text { symptoms }\end{array}$ & $57(29.1 \%)$ & 19 (25\%) & 38 (31.7\%) & 0.317 \\
\hline $\begin{array}{c}\text { Genitourinary } \\
\text { symptoms }\end{array}$ & $174(88.8 \%)$ & 74 (97.4\%) & $100(83.3 \%)$ & 0.002 \\
\hline Autonomic symptoms & II 6 (59.2\%) & 45 (59.2\%) & 7I (59.2\%) & 0.995 \\
\hline Anxious behavior & I 58 (80.6\%) & $76(100 \%)$ & $82(68.3 \%)$ & $<0.001$ \\
\hline
\end{tabular}


Table 2 Variables associated with anxiety in 196 patients with epilepsy

\begin{tabular}{|c|c|c|c|c|c|}
\hline Variable & $\begin{array}{l}\text { Subjects with anxiety } \\
(N=76)\end{array}$ & $\begin{array}{l}\text { Subjects without anxiety } \\
(N=127)\end{array}$ & $\begin{array}{l}P \text { value } \\
\text { on bivariate analysis }\end{array}$ & $\begin{array}{l}\text { Logistic } \\
\text { regression p value }\end{array}$ & Adjusted OR $(95 \% \mathrm{Cl})$ \\
\hline Polytherapy & $66(86.8 \%)$ & $75(62.5)$ & $<0.001$ & 0.780 & $1.16(0.40-3.36)$ \\
\hline Carbamazepine & $36(47.4 \%)$ & $72(60 \%)$ & 0.057 & 0.481 & $0.74(0.32-1.70)$ \\
\hline Topiramate & $4(5.3 \%)$ & 0 & 0.022 & 0.710 & |4|.26 (0-9777.0) \\
\hline Primidone & $42(55.3 \%)$ & $19(15.8 \%)$ & $<0.001$ & 0.023 & $2.94(1.15-7.49)$ \\
\hline $\begin{array}{l}\text { Lower } \\
\text { educational } \\
\quad \text { level }\end{array}$ & $73(96.1 \%)$ & $120(100 \%)$ & 0.028 & 0.848 & $753.39(0-2213)$ \\
\hline Depression & $59(77.6 \%)$ & $24(20 \%)$ & $<0.001$ & $<0.001$ & II.34 (4.92-26.25) \\
\hline $\begin{array}{l}\text { Poor seizure } \\
\text { control }\end{array}$ & $64(84.2 \%)$ & $86(71.7 \%)$ & 0.031 & 0.746 & $1.17(0.43-3.16)$ \\
\hline $\begin{array}{l}\text { Cryptogenic } \\
\text { epilepsy }\end{array}$ & $18(23.7 \%)$ & $52(43.3 \%)$ & 0.005 & 0.058 & $4.21(1.57-11.40)$ \\
\hline $\begin{array}{l}\text { Posttraumatic } \\
\text { epilepsy }\end{array}$ & $14(18.4 \%)$ & $6(5 \%)$ & 0.002 & 0.009 & $0.21(0.06-0.68)$ \\
\hline
\end{tabular}

that differentiate between patients with and without anxiety were anxious mood, tension, insomnia, intellectual function, depressed mood, cardiovascular symptoms, genitourinary symptoms and anxious behavior. This finding suggests that the effect of somatic symptoms on the frequency of anxiety in patients with epilepsy is modest, something previously reported among other patients with complex physical illness and disability (Smallbrugge et al 2005). Since the fears item of the HAMA scale is evaluated according to the presence of fears to being left alone, of crowds and of strangers among others, we think that patients with epilepsy, due to their fear to have a seizure in different settings, with different people and for that to be discriminated, could be the main reason why this item was uninformative here.

Assessment of anxiety disorders in epilepsy is difficult because anxiety symptoms such as fear are part of the seizure itself (Hughes et al 1993) and because of the overlap between depression and anxiety symptoms (Altshuler et al 1990). However, all health-related quality of life domains have been found to be significantly worse with the presence of anxiety symptoms independently of the presence of depressive symptoms (Altshuler et al 1990; Cramer et al 2005). Further efforts must be performed in order to build up a specific instrument to diagnose anxiety in this population.

One major flaw in our study is that cross-sectional design does not permit to establish the role of the psychosocial risk factors for anxiety in epilepsy which may include reactions to the unpredictable nature of epilepsy, restrictions in normal living such as driving and employment, lack of financial security and the need to depend on family members. This can lead to low self-esteem, stigmatization and social rejection
(Johnson et al 2004). Prospective studies must be performed in the future to determine the evolution of the anxiety among patients with epilepsy.

\section{Disclosure}

The authors report no conflicts of interest in this work.

\section{References}

Alanis-Guevara I, Peña E, Corona T, et al. 2005. Sleep disturbances, socioeconomic status, and seizure control as main predictors of quality of life in epilepsy. Epilepsy Behav, 7:481-5.

Altshuler LL, Devinsky O, Post RM, et al. 1990. Depression, anxiety, and temporal lobe epilepsy Laterality of focus and symptoms. Arch Neurol, 47:284-8.

Commission on Classification and Terminology of the International League Against Epilepsy. 1981. Proposal for revised clinical and electroencephalographic classification of epileptic seizures. Epilepsia, 22:489-501.

Cramer JA, Brandenburg N, Xu X. 2005. Differentiating anxiety and depression symptoms in patients with partial epilepsy. Epilepsy Behav, 6:563-9.

Currie S, Heathfield KW, Henson RA, et al. 1971. Clinical course and prognosis of temporal lobe epilepsy A survey of 666 patients. Brain, 94:173-90.

Devinsky O. 2003. A 48-year old man with temporal lobe epilepsy and psychiatric illness. JAMA, 290:381-92.

Devinsky O, Barr WB, Vickrey BG, et al. 2005. Changes in depression and anxiety after resective surgery for epilepsy. Neurology, 65:1744-9.

Edeh J, Toone B. 1987. Relationship between interictal psychopathology and the type of epilepsy. Results of a survey in general practice. $\mathrm{Br} J$ Psychiatry, 151:95-101.

Gaitatzis A, Trimble MR, Sander JW. 2004. The psychiatric comorbidity of epilepsy. Acta Neurol Scand, 110:207-20.

Gloor P, Olivier A, Quesney LF, et al. 1982. The role of the limbic system in experiential phenomena of temporal lobe epilepsy. Ann Neurol, 12:129-44.

Gureje O. 1991. Interictal psychopathology in epilepsy: prevalence and pattern in a Nigerian clinic. Br J Psychiatry, 158:700-5.

Hermann BP, Chhabria S. 1980. Interictal psychopathology in patients with ictal fear. Examples of sensory-lymbic hyperconnection. Arch Neurol, 37:667-8. 
Hermann BP. 1991. The relevance of social factors to adjustment in epilepsy. In: Devinsky O, Theodore WH (eds). Epilepsy and behavior. New York: Wiley-Liss pp. 23-36.

Hughes J, Devinsky O, Feldmann E, et al. 1993. Premonitory symptoms in epilepsy. Seizure, 2:201-3.

Jacoby A, Baker GA, Steen N, et al. 1996. The clinical course of epilepsy and its psychosocial correlates: findings from a UK Community study. Epilepsia, 37:148-61.

Johnson EK, Jones JE, Seidenberg M, et al. 2004. The relative impact of anxiety, depression, and clinical seizure features on health-related quality of life in epilepsy. Epilepsia, 13:129-35.

Kanner AM. 2002. Psychiatric comorbidity in patients with developmental disorders and epilepsy: a practical approach to its diagnosis and treatment. Epilepsy Behav, 3:7-13.

Lopez-Gomez M, Ramirez-Bermudez J, Campillo C, et al. 2005. Primidone is associated with interictal depression in patients with epilepsy. Epilepsy Behav, 6:413-6.

McConnell H, Snyder PJ, Duffy JD, et al. 1996. Neuropsychiatric side effects related to treatment with felbamate. $J$ Neuropsychiatry Clin Neurosci, 8:341-6.
Mula M, Trimble MR, Lhatoo SD, et al. 2003. Topiramate and psychiatric adverse events in patients with epilepsy. Epilepsia, 44:659-63.

Nickell PV, Uhde TW. 1999. Anxiety disorders and epilepsy. In: Devinsky O, Theodore WH (eds). Epilepsy and Behavior. New York: WileyLiss, pp. 67-84.

Perini GI, Tosin C, Carraro C, et al. 1996. Interictal mood and personality disorders in temporal lobe epilepsy and juvenile myoclonic epilepsy. $J$ Neurol Neurosurg Psychiatry, 61:601-5.

Piazzini A, Canevini MP, Maggioiri G, et al. 2001. Depression and anxiety in patients with epilepsy. Epilepsy Behav, 2:481-9.

Reynders HJ, Broks P, Dickson JM, et al. 2005. Investigation of social and emotion information processing in temporal lobe epilepsy with ictal fear. Epilepsy Behav, 7:419-29.

Smallbrugge M, Pot AM, Jongenelis L, et al. 2005. The effect of somatic symptoms attribution on the prevalence rate of depression and anxiety among nursing home patients. Int J Methods Psychiatr Res, 14:146-50.

Zimmerman M, Chelminski I, Zisook S. 2006. Recognition and treatment of depression with or without comorbid anxiety disorders. CNS Spectr, 11(1 Suppl 1):1-16. 
